\title{
Three finger palpation technique of vas deferens for keyhole vasectomy in spotted (Axis axis) and sambar deer (Cervus unicolor)
}

\author{
B. J. William, M. Bharathidasan, R. Thirumurugan, A. Arunprasad, T. A. Kananan, R. S. George, \\ L. Nagarajan and C. Ramani
}

\begin{abstract}
Department of Veterinary Surgery and Radiology, Madras Veterinary College, Tamil Nadu Veterinary and Animal Sciences University, Chennai, Tamil Nadu, India.

Corresponding author: B. Justin William, email: vetjust@gmail.com, MB: dasan.bharathi234@gmail.com, RT: thiruzoovet@googlemail.com, AA: drapvet1973@gmail.com, TAK: kanns2000@gmail.com, RSG: ravi.george@yahoo.com, LN: sriramki.krishna@gmail.com, CR: ramani@tanuvas.org.in

Received: 12-05-2014, Revised: 28-07-2014, Accepted: 31-07-2014, Published online: 13-09-2014
\end{abstract}

doi: 10.14202/vetworld.2014.685-688. How to cite this article: William BJ, Bharathidasan M, Thirumurugan R, Arunprasad A, Kananan TA, George RS, Nagarajan L, Ramani C (2014) Three finger palpationtechnique of vas deferens for keyhole vasectomy in spotted (Axis axis) and Sambar deer (Cervus unicolor), Veterinary World 7(9): 685-688.

\begin{abstract}
Aim: Vasectomy is performed in deer for population control, maintain pedigreed animals and prevent inbreeding. Conventional procedure of vasectomy required a long-term anesthesia and longer duration of hospitalization, which often result in stress, morbidity and mortality. A study was conducted to capture, neuter and release the deer with minimal hospitalization and stress by adopting three finger palpation technique of vas deferens and performing vasectomy through a key-hole incision.

Materials and Methods: The study was conducted on three spotted male deer and three sambar male deer, which were immobilized with a mixture of xylazine at the dose of $1.00 \mathrm{mg} / \mathrm{kg}$ and ketamine at the dose of $5.00 \mathrm{mg} / \mathrm{kg}$. The vas deferens could be palpated as a piece of cooked spaghetti at the neck of the scrotum on the anterior aspect by three finger palpation technique and was able to fix the vas deferens between the thumb and middle finger. Through a key-hole incision of $<5 \mathrm{~mm}$ length, the vas deferens was exteriorized and resected using electrocautery and the skin incision was sealed with methyl methacrylate. The deer were released on the same day, and no post-operative complication was noticed.
\end{abstract}

Conclusion: The study revealed that three finger palpation technique of vas deferens provided guidance for easy access to vas deferens for vasectomy in deer with less hospitalization, and the deer could be released on the same day.

Keywords: anesthesia, immobilization, ketamine, sambar deer, spotted deer, three finger palpation technique, vasectomy, xylazine.

\section{Introduction}

Wild animals are valuable natural resources and vital components of a healthy eco system. Conservation programs are focused on increasing the population which is extremely successful, and certain species are locally overabundant. Various birth control programs are adopted to control the population, maintain pedigreed animals and prevent inbreeding. Overabundant spotted deer and sambar deer often warrant appropriate population control measures. Vasectomy is a safe population control measure which is effective and also satisfies the welfare concern [1]. Complications of conventional vasectomy reported are hematomas, bleeding, bursting, infection, longer duration of anesthesia and surgery associated with stress [2] in which the skin incision is made to a length of about 4-6 cm [3].

Currently no-scalpel vasectomy in human is considered as an adorned technique with less complication, wherein the vas deferens is located, fixed and scrotal skin is punctured to access the vas deferens using a scalpel or no-scalpel method, popularized by

Copyright: The authors. This article is an open access article licensed under the terms of the Creative Commons Attributin License (http:// creative commons.org/licenses/by/2.0) which permits unrestricted use, distribution and reproduction in any medium, provided the work is properly cited.
Li et al. [4]. Deer being highly susceptible to stress, they have to be chemically restrained with appropriate anesthetic drugs and immobilization techniques. Early release or less hospitalization is an ideal practice for less morbidity and mortality which warrants minimal scrotal incision and no post-operative complication.

The key-hole surgical procedure of vasectomy described was performed by palpation of vas deferens by three finger technique.

\section{Materials and Methods}

The three male spotted deer aged between 4 and 6 years and three male sambar deer aged between 4 and 5 years were chemically immobilized with xylazine and ketamine each at the dose of $1.00 \mathrm{mg} / \mathrm{kg}$ and $5.00 \mathrm{mg} / \mathrm{kg}$ respectively through a dart syringe using a blow gun. The sambar deer weighed between 60 and $115 \mathrm{~kg}$ and the spotted deer weighed between 50 and $65 \mathrm{~kg}$. After immobilization, the animals were positioned under right lateral recumbency. Two sambar deer required additional dose of ketamine, which was administered using handheld syringe at the dose of $2.50 \mathrm{mg} / \mathrm{kg}$. The upper hind limb was pulled cranially to expose the scrotum. The procedure described is for a right handed surgeon. The scrotum and adjacent site were prepared for aseptic surgery. The spermatic cord of the lower testis 
was grasped at the neck of the scrotum with three fingers; the middle finger below and the thumb and index fingers above, crossing the neck of the scrotum to expose the anterior aspect (Figure-1), so as to enable the surgeon to lift the spermatic cord upwards with the middle finger. The spermatic cord was palpated and swept towards the median raphe with the thumb. By gentle to and fro movement of the thumb over the spermatic cord and upward pressure from the middle finger and downward pressure from the index finger and thumb the vas deferens was felt as a piece of cooked spaghetti at the caudal aspect of the spermatic cord and fixed in position between the thumb and middle finger. A small skin incision of $<5 \mathrm{~mm}$ was made cranial to the thumb using No. 10 Bard Parker blade at the neck of the scrotum to pierce the scrotal skin (Figure-2) and tunica vaginalis and the vas deferens was exposed (Figure-3). The vas deferens appeared as a glistening milky white tubular structure and was lifted as a loop using a hemostat (Figure-4). The exteriorized loop around 1 inch length was resected using electrocautery. The same procedure was repeated for the other vas deferens, where the vas deferens was swept away from the median raphe. Both the wounds of $5 \mathrm{~mm}$ were sealed with methyl methacrylate skin glue. The deer

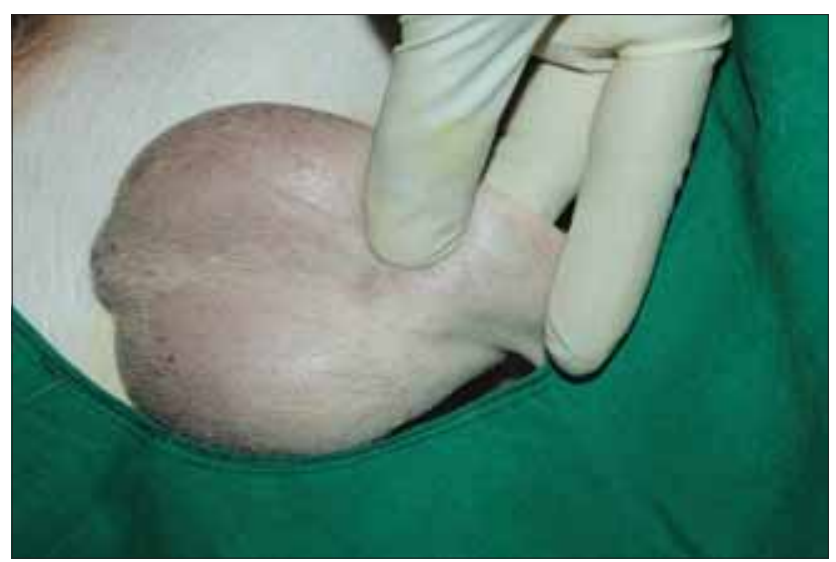

Figure-1: Position of fingers for holding scrotum - three finger palpation technique of vas deferens.

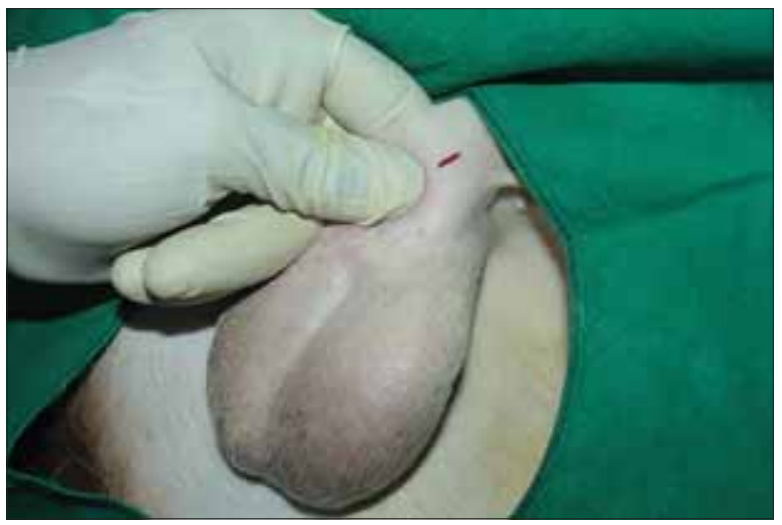

Figure-2: Key-hole incision cranial to thumb over the fixed vas deferens. were immunized with tetanus toxoid $5 \mathrm{Lf}$ units and were released after recovery. The deer was observed post-operatively.

\section{Results}

The dose of xylazine and ketamine at the rate of $1.00 \mathrm{mg}$ and $5.00 \mathrm{mg} / \mathrm{kg}$ induced good immobilization to restrain the spotted and sambar deer on lateral recumbency without physical restraint. Sambar deer required additional dose of ketamine. The time taken for induction of immobilization was $12.64 \pm 1.52 \mathrm{~min}$ and the duration of immobilization and anesthesia was $25.33 \pm 2.76 \mathrm{~min}$, which was sufficient to perform bilateral vasectomy and the mean duration of surgery was $8.12 \pm 1.54 \mathrm{~min}$. No intra-operative complication was recorded.

The scrotal skin was thicker in deer, and the vas deferens could be palpated between the thumb and middle finger on the anterior aspect of the neck of the scrotum rather than the posterior aspect as a piece of cooked spaghetti. Small puncture over the secured vas deferens sufficiently penetrated the scrotal skin and tunica vaginalis, through which the vas deferens could be visualized as a glistening milky white color tubular structure. Electrocautery was applied following exteriorization of the vas deferens for resection and no ligature was applied. The key-hole incision was

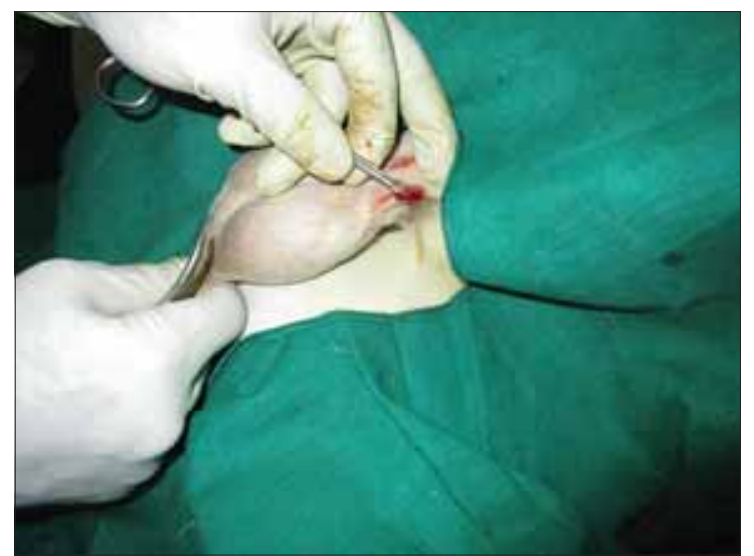

Figure-3: Exposed vas deferens - confirmed by milky white glistening surface.

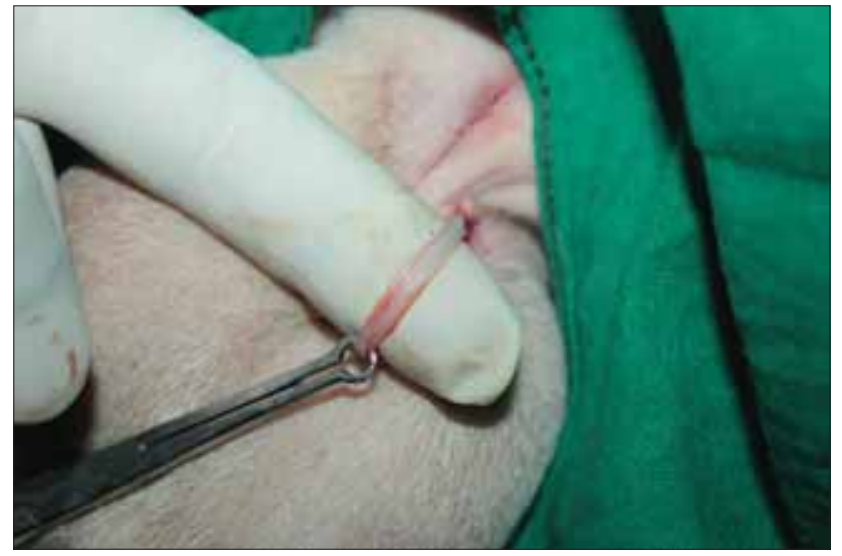

Figure-4: Exteriorized loop of vas deferens for electrocautery. 
sealed with methyl methacrylate skin glue. Following recovery the deer were released and no post-operative complication was noticed.

\section{Discussion}

Xylazine-ketamine combination at the dose of 1.00 and $5.00 \mathrm{mg} / \mathrm{kg}$ respectively induced immobilization and anesthesia with good muscle relaxation for a period of $25 \mathrm{~min}$, which was sufficient for the entire procedure of bilateral vasectomy by three finger palpation technique and key-hole incision; revealing xylazine and ketamine combination was a safe and effective anesthetic regimen in spotted and sambar deer for immobilization and minor surgical or diagnostic procedures [5,6].

Three finger palpation technique of vas deferens was described for no-scalpel vasectomy in man [4,7-9]. Under palpation, the vas deferens could easily be fixed, exteriorized and lifted using a hemostat through the key-hole incision. The bundle of spermatic cord was not exteriorized or no traction was applied as in conventional open technique [2,3], which might result in pain, swelling and infection [10]. Complications reported earlier following vasectomy such as bleeding, pain, swelling and delayed wound healing were not observed because finger palpation technique provided guidance for easy access of vas deferens through a key-hole incision with minimal tissue damage, less bleeding and no complication. Electrocautery was found to be safe and effective without failures [11-13].

The time taken for bilateral vasectomy was less than the conventional vasectomy procedure, due to shorter duration of recumbency, anesthesia, minimal ventilation-perfusion mismatch [14] and requirement of additional doses of anesthetic drugs $[15,16]$. Stress and stress related complications like hyperthermia $[17,18]$, captive myopathy $[19,20]$ and mortality were thereby avoided. Animals could be released on the same day following recovery.

\section{Conclusion}

Three finger palpation technique of vas deferens provided guidance for easy access to vas deferens through key-whole incision for vasectomy and early release of deer without complication.

\section{Authors' Contributions}

BJW evolved the technique of three finger palpation and performed the surgeries with AA, RSG and LN. MB and RT managed the immobilization and anaesthesia. TAK and CR were involved in the post-operative care and management. All the authors participated in draft and revision of manuscript.

\section{Acknowledgments}

The authors would like to thank the Dean, Madras Veterinary College, Director of Clinics and
Director of Arignar Anna Zoological Park, Chennai, Tamil Nadu, India, for necessary facilities and financial support for the procurement of anaesthetics, surgical disposables and drugs.

\section{Competing I nterests}

The authors declare that they have no competing interests.

\section{References}

1. Hobbs, N.T., Bowden, D.C. and Baker, D.L. (2000) Effects of fertility control on populations of ungulates: General, stage-structured models. J. Wildl. Manage., 64: 473-491.

2. Kumar, V. and Raj, A. (2012) No-scalpel vasectomy by electrocuterization in free range rhesus macaques (Macacamulatta). Open Vet. J., 2: 6-9.

3. Kumar, V. and Raj, A. (2011) Vasectomy in captive Sambar stags (Cervus unicolor). Int. J. Agro Vet. Med. Sci., 5: 397-400.

4. Li, S.Q., Goldstein, M., Zhu, J. and Huber, D. (1991) The no-scalpel vasectomy. J. Urol., 145(2): 341-344.

5. Galka, M.E., Aguilar, J.M., Quevedo, M.J. and Villamandos, R.J.M. (1999) Alpha-2-agonist dissociative anesthetic combinations in fallow deer. J. Zoo. Wildl. Med., 30: 451-453.

6. Jessup, D.A., Clarkp, W.E., Gulleit, A. and Jones, K.R. (1983) Immobilization of mule deer with ketamine and xylazine and reversal of immobilization with yohimbine. J. Am. Vet. Med., 183(11): 1339-1340.

7. Bhuyan,K., Ali I, and Barua, S.A. (2012) Role of no scalpel vasectomy in male sterilization. Indian. J. Surg., 74(4): 284-287.

8. Muller, A.K.J. (2012) The occasional non-scalpel vasectomy. Can. J. Rural Med., 17(3): 105-109.

9. Ramasamy, R. and Schlegel, P.N. (2011) Vasectomy and vasectomy reversal: An update. Indian. J. Urol., 27(1): 92-97.

10. Goldstein, M. (1989) Vasectomy and its reversal. Hosp. Med., 2: 113-135.

11. Barone, M.A.,Irsula, B., Chen-Mok, M. and Sokal, D.C. (2004). Effectiveness of vasectomy using cautery. BMC Urol., 4: 10.

12. Labrecque, M., Dufresne, C., Barone, M.A. and St-Hilaire, K. (2004) Vasectomy surgical techniques: A systematic review. BMC. Med., 2: 21.

13. Mousavi, S.M.N., Fanaieand S.A. and Ziaee, S.A. (2007) Benefit of vasectomy using cautery in comparison with excision and ligation. J. Clin. Diagn. Res., 1: 45-49.

14. Jurado, O.M., Jud, R., Muggli, E. and Wolfensberger, B.R. (2011) Balanced anaesthetic approach in a late-term gravid cow undergoing metacarpal fracture repair. Case. Rep. Vet. Med., 2011: 1-5.

15. Auer, U., Wenger, S., Christoph, B., Zenker, W., and Mosing., M. (2010) Total intravenous anesthesia with midazolam, ketamine, and xylazine or detomidine following induction with tiletamine, zolazepam, and xylazine in red deer. J. Wildl. Dis., 46: 1196-1203.

16. Monteith, K.L., Monteith, K.B., Delger, J.A., Schmitz, L.E., Brinkman, T.J., Deperno, C.S. and Jenks, J.A. (2012) Immobilization of white-tailed deer with telazol, ketamine, and xylazine, and evaluation of antagonists. J. Wildl. Manage., 76: 1412-1419.

17. Miller B.F, Osborn D.A, Lance W.R, Howze M.B, Warren R.J. and Miller K.V. (2009) Butorphanol-azaperonemedetomidine for immobilization of captive white-tailed deer. J. Wildl. Dis., 45: 457-67.

18. Jessica Siegal-Willott, J., Citino, S.B., Wade, S., Laura E., Hayek, C.L. and Lance W.L. (2009) Butorphanol, azaperone, and medetomidine anesthesia in free-ranging whitetailed deer (Odocoileus virginianus) using radiotransmitter darts. J. Wildl. Dis., 45(2): 468-80. 
19. Ozlem, N.H., Ozak, A., Cenk, Y. and Sinan, S.Y. (2010) Treatment results of traumatic injuries in 20 roe deer (Capreolus capreolus): A retrospective study. Kafkas Univ. Vet. Fak. Derg., 16: 617-622.
20. Montane, J., Marco, I., López, O., Perpin, D., Manteca, X., and Lavín, S. (2003) Effects of acepromazine on capture stress in roe deer (Capreolus capreolus). J. Wildl. Dis., 39(2): 375-386.20.

$* * * * * * * *$ 